\title{
Caterpillar seed predators mediate shifts in selection on flowering phenology in their host plant
}

\author{
Alicia Valdés ${ }^{1}$ AND JOHAN EHRLÉN \\ Department of Ecology, Environment and Plant Sciences, Stockholm University, Stockholm, SE-106 91 Sweden
}

\begin{abstract}
Variation in selection among populations and years has important implications for evolutionary trajectories of populations. Yet, the agents of selection causing this variation have rarely been identified. Selection on the time of reproduction within a season in plants might differ both among populations and among years, and selection can be mediated by both mutualists and antagonists. We investigated if differences in the direction of phenotypic selection on flowering phenology among 20 populations of Gentiana pneumonanthe during 2 yr were related to the presence of the butterfly seed predator Phengaris alcon, and if butterfly incidence was associated with the abundance of the butterfly's second host, Myrmica ants. In plant populations without the butterfly, phenotypic selection favored earlier flowering. In populations where the butterfly was present, caterpillars preferentially attacked early-flowering individuals, shifting the direction of selection to favoring later flowering. Butterfly incidence in plant populations increased with ant abundance. Our results demonstrate that antagonistic interactions can shift the direction of selection on flowering phenology, and suggest that such shifts might be associated with differences in the community context.
\end{abstract}

Key words: community context; Gentiana pneumonanthe; myrmecophily; Myrmica; Phengaris alcon; phenotypic selection; plant phenology; plant-animal interactions; predispersal seed predation; spatial variation; timing of reproduction.

\section{INTRODUCTION}

Timing of reproduction within a season is a key trait influencing interactions both with the physical environment and with other organisms. For plants in temperate regions, selection on flowering phenology is mediated by abiotic conditions (Franks et al. 2007, Giménez-Benavides et al. 2011) and by species interactions (Elzinga et al. 2007, Sletvold et al. 2015). Pollinators might select for both earlier (e.g., Munguía-Rosas et al. 2011a, Chapurlat et al. 2015), and later flowering (e.g., Sandring and Ågren 2009). Likewise, antagonistic interactions with herbivores or pre-dispersal seed predators might favor both later (e.g., Parachnowitsch and Caruso 2008, König et al. 2015) and earlier flowering (e.g., Fukano et al. 2013, Austen and Weis 2015). Moreover, plants can simultaneously experience selection for earlier and later flowering mediated by different agents. For example, flowering early might be advantageous for plants at northern latitudes because it increases pollinator availability and the time available for seed development (Munguía-Rosas et al. 2011b), but at the same time costly if early flowering increases exposure to antagonists. In these cases, net selection depends on the relative strengths of these interactions (e.g., Ehrlén and Münzbergová 2009, Sletvold et al. 2015).

Manuscript received 19 February 2016; revised 3 October 2016; accepted 17 October 2016. Corresponding Editor: Matthew L. Forister

1E-mail: alicia.valdes@su.se
Spatial variation in selection mediated by species interactions has been documented in many systems (Thompson 2005, Siepielski et al. 2013), and may result in local adaptation and adaptive population divergence. For plantanimal interactions, differences in selection on plant traits among populations or years have been shown to be associated with differences in both interaction intensities (Benkman 2013, Benkman et al. 2013, Vanhoenacker et al. 2013), and trait preferences (Rey et al. 2006, Kolb et al. 2007b). Interaction intensities and animal preferences for plant traits might, in turn, depend on abiotic conditions (Arvanitis et al. 2007, Kolb \& Ehrlén, 2010; von Euler et al. 2014) and the community context, in terms of natural enemies, competitors or alternative hosts (Strauss and Irwin 2004, Siepielski and Benkman 2007, Chamberlain et al. 2014). Despite an increasing awareness of the importance and ubiquitous presence of spatial and temporal variation in selection, we know little in general about how biotic selective agents contribute to this variation as well as the environmental factors influencing the impact of a given selective agent. In particular, the role of biotic interactions in driving among-population variation in selection on timing of reproduction has been little explored.

Antagonistic interactors, such as seed predators, have the potential to mediate selection on plant traits, such as timing of flowering, through their preferences for particular plant phenotypes. For example, large Blue butterflies of the genus Phengaris Doherty, 1891 (the senior synonym of Maculinea van Eecke, 1915) are specialist predispersal seed predators during their first larval 
instars, and often show strong preferences for particular plant developmental stages (Thomas and Elmes 2001, Van Dyck and Regniers 2010). This means that plant individuals for which the developmental stage preferred for oviposition coincides with the peak of butterfly activity suffer most from seed predator attacks. Phengaris larvae also need a second host to complete their development, and most species are parasites of ant nests (Myrmica spp.) during later instars (Als et al. 2004). Butterfly-mediated selection on plant traits in this system might thus be influenced by the community context, if the incidence and intensity of predation are related to host ant abundance. In this study, we asked if amongpopulation variation in phenotypic selection on flowering phenology in the perennial herb Gentiana pneumonanthe is the result of differences in the intensity of interactions with its specialist predispersal seed predator, the caterpillar of the butterfly Phengaris alcon, and if variation in the incidence of the butterfly in plant populations is associated with the community context in terms of the abundance of the second host, Myrmica ants. As developmental stages preferred for oviposition in early-flowering plants usually coincide with the oviposition period of the butterfly (A. Valdés and J. Ehrlén, personal observation), we hypothesized that: (1) The presence of the butterfly seed predator in plant populations shifts the direction of phenotypic selection on flowering phenology in G. pneumonanthe, from favoring early flowering to favoring late flowering, and (2) Community context, in terms of host ant abundance, is related to the probability of butterfly presence within plant populations. To test these hypotheses, we assessed selection gradients for flowering phenology, seed predation intensities and ant abundances in $11 \mathrm{G}$. pneumonanthe populations where the butterfly was present and nine where it was absent.

\section{Methods}

Study system

The marsh gentian (Gentiana pneumonanthe L.) is a rare, long-lived perennial herb (10-20 yr, Oostermeijer et al. 1992), occurring in open habitats, such as wet heathlands and grasslands (Simmonds 1946). In natural populations, individuals do not flower until their third year (Simmonds 1946). Plants can have one to many, up to $45 \mathrm{~cm}$ high, shoots and produce deep blue flowers that are pollinated by bumblebees. The species is self-compatible and flowers in July and August in SW Sweden. Fruits are capsules containing a high number (usually 300-700, Appelqvist et al. 2007) of minute (mean seed weight $=0.044 \mathrm{mg}$, Simmonds 1946), wind-dispersed seeds. Gentiana pneumonanthe is the primary host of the Alcon Blue butterfly (Phengaris alcon), a specialist predispersal seed predator which oviposits on young buds in July and August (Appelqvist et al. 2007). The caterpillars feed inside the capsule until they reach the fourth-instar, when then they drop to the ground to be picked up by Myrmica ants (Mouquet et al. 2005).
Caterpillars mimic the surface chemistry of the ant brood (Nash et al. 2008) and the acoustic signals of queen ants (Sala et al. 2014), and this makes ants carry them to their nest, where they spend the rest of their larval period as parasites (Mouquet et al. 2005). Distinct from the majority of Phengaris species, which prey on ant brood, P. alcon is a "cuckoo" species (Als et al. 2004), and larvae feed primarily on regurgitations from ant workers, trophic eggs (i.e., nutritious, infertile eggs which are fed to the queens and larvae) and prey items brought to the nest by ants. Only ants belonging to the genus Myrmica can act as second hosts of $P$. alcon (Mouquet et al. 2005). In our study area, $M$. ruginodis is thought to be the most commonly used host ant species (Appelqvist et al. 2007).

\section{Data collection}

The study was carried out in 20 populations of G. pneumonanthe located in the county of Västra Götaland in SW Sweden (see Appendix S1 for details). The populations are mainly located in moist heathlands. The butterfly seed predator $P$. alcon was present in 11 of the study populations and absent from nine.

We collected data on plant reproductive traits, interaction intensity and plant fitness in 100 marked individuals in each of the 20 study populations during 2010 and 2011. The number of shoots per individual ranged from 1 to 44 (mean $=3)$. For recordings, we selected one focal shoot in each individual as the one having median length among all the shoots belonging to the same individual. In these focal shoots, we recorded shoot height (in $\mathrm{cm}$ ), number of flowers, and developmental stage of each bud and flower. Buds and flowers were assigned to one of six developmental stages: (1) the sepals covering the bud completely; (2) bud becoming visible; (3) bud growing over the sepals; (4) bud turning blue; (5) flower opening, and (6) flower showing signs of wilting. Each of these stages corresponded to a time interval of flower development, and the average duration of stages 2-5 was about 1 week during this study (A. Valdés, personal observation). All plant traits were measured once per year, at the end of July-beginning of August. Phenology of plant individuals was estimated based on the reproductive development stage of flowers at the day of recording. We calculated two different phenology measures: (1) the mean development stage of all flowers and buds within the focal shoot (a continuous variable ranging from 1 to 6 ), and (2) the stage of the most advanced bud within the focal shoot (an ordinal variable ranging from 1 to 6). In both cases, higher values indicate a more advanced floral development at the day of recording, i.e., an earlier flowering. According to the observed average duration of the stages, a one-unit increase in these measures roughly corresponds to 1 week earlier development. Our method to assess differences in timing of development among individuals differs from the traditional method to record the calendar date at which an individual reaches a predefined stage of development, e.g. the opening of the first flower. We 
chose this method because we considered it to be advantageous in two important respects. First, given that recordings are made synchronously and at a relevant stage, it allows for an assessment of differences in development among a large number of individuals during a single recording. Second, it provides a measure of differences in the state of development that is much less dependent on differences in ambient temperature and thus more adequate for assessments of selection. For example, an individual with large buds (i.e., in a later development state) and an individual with just opened flowers (i.e., in an earlier development state) might differ by one or $2 \mathrm{~d}$ in first flowering date if temperatures are high but by several days if temperatures are lower and development of floral structures slower. Hence, the difference in first flowering date that is associated with a given difference in developmental stage at a given date will depend on temperature during the subsequent period. At the same time, it is clear that one possible disadvantage of measuring developmental rate at one occasion is that unstandardized estimates might be difficult to compare among populations if recordings are not carried out simultaneously. However, in the current study visits to the different populations were made within a short period of time, and our measure of phenology was not related to the date of recording in any of the $2 \mathrm{yr}$ (linear regression of population mean phenology vs. recording date; 2010: $t=-1.01, P=0.326,2011: t=0.89, P=0.388$ ).

Interaction intensity was estimated by the maximum number of $P$. alcon eggs observed on the focal shoot during 2-6 visits to each population. Populations were visited once at the end of July-beginning of August (when data on reproductive traits was collected) and from 1 to 5 times from the end of August until all fruits had matured in mid-October (the number of visits depending on the time needed for fruit maturation). During these visits, we also counted the number of fruits, flowers and buds damaged by the caterpillar (i.e., showing exit holes made by the larvae).

Plant fitness was estimated by the maximum observed number of intact (i.e., not damaged by the caterpillar) mature fruits on the focal shoot (assessed from counts of fruits on 1 to 5 visits to each population, see above). Although some seeds might remain in attacked fruits, the larvae consume a large proportion of seeds in the capsules (A. Valdés, personal observation), and the total number of mature seeds in intact and attacked fruits is strongly correlated with the number of intact fruits ( $r=0.85, \mathrm{~N}=1,136$ individuals in 2010). In 2010, information on fruit production was collected in all 20 populations but in 2011 we were only able to get information from 16 of the populations.

Ant abundance was estimated once per study year along transects in each of the 20 study populations. In 2010, $20-\mathrm{m}$ transects were established, and in 2011 we used a $40-\mathrm{m}$ transect in each population. Sugar cubes were placed at one-meter intervals along the transects, and the number of Myrmica sp. ants at each of the sugar cubes was counted
30 min after presenting them to ants. Assessments were only carried out under dry (no precipitation) and warm conditions. To further reduce variation due to varying weather conditions during ant counts, we used the highest yearly value of the average number of ants per sugar cube in each population as a measure of ant abundance.

\section{Statistical analyses}

To assess phenotypic selection on flowering phenology, we performed selection gradient analyses in each of the $2 \mathrm{yr}$ by regressing relative fitness on standardized estimates of phenology, flower number and shoot height (Lande and Arnold 1983). Fitness, in terms of the number of intact fruits, was relativized within populations by dividing individual values by population mean values. Traits were standardized by subtracting the population mean and dividing by the population standard deviation. Linear effects of trait on fitness were estimated in models without quadratic or interaction terms. To test for differences in phenotypic selection gradients among populations, we included the interaction between standardized reproductive traits and population in the models. The main effect of population was not included as fitness was relativized within populations prior to analysis. In addition to tests of directional (linear) selection, we also tested for nonlinear (quadratic and correlational) selection. Quadratic selection is defined as the covariance between relative fitness and the squared deviations of trait values from the mean, while correlational selection is the covariance between relative fitness and the product of trait deviations (Lande and Arnold 1983, Arnold 1986). Non-linear selection was assessed by examining the effects of quadratic and interaction terms in a model including also the linear terms. Results for models using mean and most advanced flower developmental stages within shoots as estimates of phenology were very similar in all cases. Below, we present only results for the stage of the most advanced bud (results for selection gradient analyses using the mean flower developmental stage are shown in Appendix S2).

To test if linear selection on reproductive traits differed among populations with vs. without $P$. alcon, and to avoid basing contrasts on estimates of selection coefficients without accounting for the errors of these estimates, we created a variable "Predation," coded as 0 in populations without $P$. alcon and as 1 in populations with $P$. alcon, and constructed a linear mixed model for each year. Predictors included standardized reproductive traits, predation and trait $\times$ predation interactions as fixed effects, and trait $\times$ population interactions as random effects nested within predation. We did not include an individual intercept by population because fitness was relativized within populations prior to analysis.

In populations where the butterfly seed predator was present, we investigated predator preferences, by regressing the probability ( 0 or 1 ) and intensity (number of eggs in all individuals) of attack by $P$. alcon on standardized reproductive traits, population and their interactions in each of 
the 2 yr. We excluded population D (Appendix S1) in 2010 from these analyses because only one plant individual was attacked.

We also used path analyses (Grace 2006) to examine the relative importance of direct and indirect effects of reproductive traits on fitness in the populations where the butterfly seed predator was present (excluding population D in 2010 for the same reason stated above). We considered indirect effects to be mediated by either the intensity of predation or the probability of attack (Appendices S3-S5). We constructed saturated models that included direct effects of phenology, flower number and shoot height on number of intact fruits, effects of these traits on predation by $P$. alcon, and the effect of predation on number of intact fruits. We also included correlations between reproductive traits. We first fit global models for each of the $2 \mathrm{yr}$ using data from all populations. Before analysis, all data were standardized within populations by subtracting the population mean and dividing by the population standard deviation. For each of the $2 \mathrm{yr}$, we considered possible alternatives to the saturated model by constructing nested models, and selected the model with lowest AICc. The overall fit of this model was evaluated using the Bollen-Stine bootstrap test (Bollen and Stine 1993) based on 5000 bootstrap samples. We then used multigroup analysis (Grace 2006), to test for differences among populations in path coefficients. This analysis evaluates if the parameters in the model differ between groups (i.e., populations in our case). We first evaluated the most restrictive hypothesis of equality of all path coefficients between populations, and then we imposed equality constraints on individual paths and examined the effect of these constraints on overall model fit (Appendix S6). The constraints for which the imposition of the equality assumption causes a significant decrease in the chi-square value indicate path coefficients that are significantly different between groups. Because the multigroup analysis indicated that several path coefficients differed among populations, we fitted separate saturated path models to each population. The adequacy of the hypotheses of our causal models to our data (given by a non-significant $\chi^{2}$ value) was not a major issue here, as our aim here was to compare the relationships depicted in these models among populations (cf. Rey et al. 2006). As data departed from multivariate normality (results not shown), we calculated bootstrap parameter estimates and test statistics for path coefficients, based on 5000 bootstrap samples.

Finally, we examined if the abundance of the host ant of $P$. alcon was associated with an increased probability of predator presence or an increased interaction intensity. First, we performed a logistic regression of butterfly seed predator presence on log-transformed ant abundance, using the 20 study populations. Second, we regressed the mean number of eggs per plant and the proportion of plants with $P$. alcon eggs in each of the $2 \mathrm{yr}$ on logtransformed ant-abundance, using the 11 populations where the butterfly seed predator was present.
Path analyses were carried out in Amos 16.0 (Arbukle 2007). All other analyses were conducted in R 3.1.2 ( $R$ Development Core Team, 2014).

\section{RESUlTS}

Directional phenotypic selection on flowering phenology varied among populations, and was statistically significant in five populations in 2010, and in three populations in 2011 (Table 1A, Appendix S7). Selection gradients for phenology varied among populations as well as between years within populations (populations: 2010: $\mathrm{SD}=0.29,2011: \mathrm{SD}=0.25$; between years: mean SD across populations $=0.10$ ). Among-population variation in selection on flowering phenology was strongly associated with the incidence of the butterfly seed predator in plant populations (Table 2, Appendix S7). In populations where the butterfly was absent, there was selection for earlier flowering (mean $\pm 95 \% \mathrm{CI}$ of selection gradients, 2010: $0.22 \pm 0.15,2011: 0.30 \pm 0.17$ ), while in populations where the butterfly was present there was selection for later flowering (mean $\pm 95 \%$ CI of selection gradients, 2010: $-0.19 \pm 0.15,2011:-0.10 \pm 0.11$, Fig. 1). The intensity of selection varied also among populations with the butterfly (Appendix S7, selection gradients for flowering phenology among populations with the seed predator: 2010: $\mathrm{SD}=0.22 ; 2011: \mathrm{SD}=0.19)$. Differences in selection gradients for phenology among populations with the butterfly were not significantly related to predation intensity, in terms of the mean number of eggs per individual (2010: $\beta$ $=-0.01, P=0.808 ; 2011: \beta=-0.03, P=0.080$ ).

We found evidence of directional selection also on flower number and shoot height. Selection on flower number varied among populations in both study years (Table 1A), but this variation was not associated with the incidence of the butterfly seed predator in plant populations (Table 2). There was no selection on shoot height in 2010, while in 2011 selection differed between populations with and without the seed predator (Tables 1A and 2). We also found evidence of non-linear selection, in terms of quadratic effects of flower number and correlational effects of flower number $\times$ phenology, and these effects varied among populations (Table 1B).

In both study years, early development of floral structures increased the probability of being attacked by the butterfly seed predator within all populations where it was present (Table 3). The probability of being attacked was higher in plants with higher numbers of flowers in 2011, while the effect of flower number differed among populations in 2010. Shoot height did not influence probability of attack in any of the two study years. Also the number of eggs per plant was correlated with phenology and flower number within populations, but the relationships varied among populations in both study years (most relationships were positive, although they varied in strength, Tables 3 and 4, Appendix S8).

Global path analyses showed that an earlier flowering phenology had a negative effect on fitness through effects 
TABLE 1. Selection gradient analyses for three traits, flowering phenology, flower number, and shoot height, in G. pneumonanthe in 2010 ( $\mathrm{N}=2000$ plants in 20 populations) and 2011 ( $\mathrm{N}=1598$ plants in 16 populations). Results are from linear models, including: (A) only linear effects, (B) linear, quadratic and interaction effects. All models included effects of population $\times$ trait interactions. Fitness was estimated by the number of intact fruits. Traits were standardized and fitness relativized within populations before analyses.

\begin{tabular}{|c|c|c|c|c|}
\hline \multirow[b]{2}{*}{ Source of variation } & \multicolumn{2}{|c|}{2010} & \multicolumn{2}{|c|}{2011} \\
\hline & $\mathrm{df}$ & $F$ & $\mathrm{df}$ & $F$ \\
\hline \multicolumn{5}{|l|}{ (A) Linear terms } \\
\hline Phenology (early flowering) & 1 & 1.59 & 1 & 0.42 \\
\hline Flower number & 1 & $19.30 * * *$ & 1 & $8.78 * *$ \\
\hline Shoot height & 1 & 0.37 & 1 & 2.41 \\
\hline Population $\times$ Phenology & 19 & $3.61 * * *$ & 15 & $1.98 *$ \\
\hline Population $\times$ Flower number & 19 & $3.88 * * *$ & 15 & $2.90 * * *$ \\
\hline Population $\times$ Shoot height & 19 & 1.19 & 15 & $2.35 * *$ \\
\hline \multicolumn{5}{|l|}{ (B) Non-linear terms } \\
\hline Phenology 2 & 1 & 0.01 & 1 & 0.04 \\
\hline Flower number ${ }^{2}$ & 1 & 1.28 & 1 & 0.77 \\
\hline Shoot height 2 & 1 & 1.74 & 1 & 0.04 \\
\hline Population $\times$ Phenology 2 & 19 & 0.64 & 15 & 1.31 \\
\hline Population $\times$ Flower number 2 & 19 & $1.88 *$ & 15 & $2.82 * * *$ \\
\hline Population $\times$ Shoot height 2 & 19 & 1.00 & 15 & 0.73 \\
\hline Phenology $\times$ Flower number & 1 & 2.66 & 1 & 0.01 \\
\hline Phenology $\times$ Shoot height & 1 & 0.63 & 1 & 0.10 \\
\hline Flower number $\times$ Shoot height & 1 & 1.24 & 1 & 0.64 \\
\hline Population $\times$ Phenology $\times$ Flower number & 19 & $2.39 * * *$ & 15 & $2.42 * *$ \\
\hline Population $\times$ Phenology $\times$ Shoot height & 19 & 0.63 & 15 & 0.76 \\
\hline Population $\times$ Flower number $\times$ Shoot height & 19 & 1.06 & 15 & $2.14^{* *}$ \\
\hline
\end{tabular}

$* P<0.05 ; * * P<0.01 ; * * * P<0.001$.

on the intensity of predation and the probability of predator attack in both years (Fig. 2, Appendix S3). Early phenology also had a direct negative effect on fitness in 2010. In both study years, a higher flower number had a direct positive effect on fitness, but a negative indirect effect mediated by predation, the net effect being positive. There were no effects of shoot height on predation or fitness. Multigroup path-analyses revealed significant among-population differences in trait-fitness relationships
(Appendix S6). Models fitted for each population and year showed that effect sizes varied among populations and between years, but that there were consistent direct and indirect effects of phenology and number of flowers on fitness (Table 4, Appendices S4, S5 and S9). On average, advancing phenology by one stage (i.e., flowering approximately one week earlier) leads to an additional 0.87 eggs laid per plant (Appendix S9). Each additional egg laid on a plant, in turn, reduced the number of intact fruits by on

TABLE 2. Selection gradient analyses for three traits, flowering phenology, flower number, and shoot height, in G. pneumonanthe in $2010(\mathrm{~N}=2000$ plants in 20 populations $)$ and $2011(\mathrm{~N}=1598$ plants in 16 populations). The presence of butterfly seed predators (Predation), coded as 0 in populations without butterflies and as 1 in populations with butterflies, was included in all models, as well as the interactions predation $\times$ trait and population $\times$ trait (the latter included as random effects nested within predation, not shown). Results are from linear mixed models (Wald $\chi^{2}$ values are shown). Fitness was estimated by the number of intact fruits. Traits were standardized and fitness relativized within populations before analyses.

\begin{tabular}{|c|c|c|c|c|}
\hline \multirow[b]{2}{*}{ Source of variation } & \multicolumn{2}{|c|}{2010} & \multicolumn{2}{|c|}{2011} \\
\hline & df & $\chi^{2}$ & df & $\chi^{2}$ \\
\hline Phenology (early flowering) & 1 & $8.60 * *$ & 1 & $13.53^{* * *}$ \\
\hline Flower number & 1 & $22.09 * * *$ & 1 & 2.41 \\
\hline Shoot height & 1 & 2.11 & 1 & 2.83 \\
\hline Predation & 1 & 0.16 & 1 & 0.00 \\
\hline Predation $\times$ Phenology & 1 & $15.38 * * *$ & 1 & $14.95^{* * *}$ \\
\hline Predation $\times$ Flower number & 1 & 0.01 & 1 & 3.69 \\
\hline Predation $\times$ Shoot height & 1 & 0.04 & 1 & $5.69 *$ \\
\hline
\end{tabular}

$* P<0.05 ; * * P<0.01 ; * * P<0.001$. 


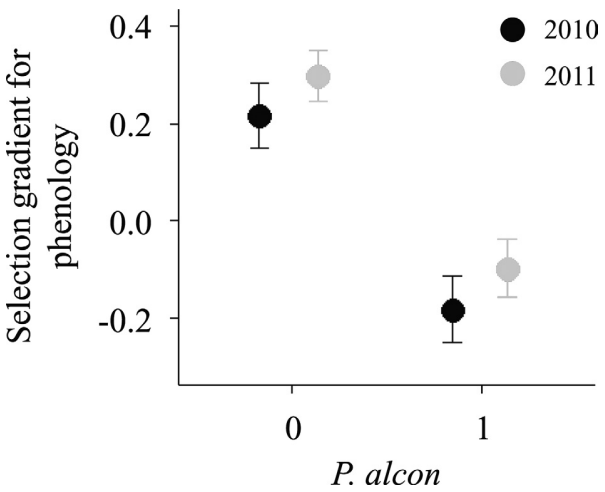

FIG. 1. Differences in linear selection gradients for flowering phenology between populations where the butterfly seed predator was present $(P$. alcon $=1, \mathrm{~N}=11)$ and absent $(P$. alcon $=0, \mathrm{~N}=9)$ in 2010 and 2011. Filed circles represent means, and bars standard errors $(P<0.001$ in both years, oneway ANOVAs).

average 0.08 (Appendix S9), meaning a butterfly-mediated reduction in fitness of a one-stage advancement in phenology by 0.07 intact fruits, corresponding to about 35 seeds (based on that intact fruits on average contain 500 seeds, Appelqvist et al. 2007, A. Valdés and J. Ehrlén, unpublished data). Plant individuals in populations where the butterfly was present produced on average $15 \%$ less intact fruits in 2010 (0.83 vs. 0.97$)$ and $20 \%$ less intact fruits 2011 (0.61 vs. 0.76) compared with plants in populations where the butterfly was absent. Among populations with the butterfly, predation explained $26.4 \%$ of the variation in mean fitness $\left(R^{2}\right.$-value from a linear model with each population in each year as replicates). Within populations with the butterfly, caterpillar damage explained between $0.2 \%$ and $49.5 \%$ (mean $=27.7 \%, R^{2}$-values from Poisson GLMs) of the total variation in fitness.

The probability of $P$. alcon presence increased significantly with increasing abundance of Myrmica ants in the population (Fig. 3). Although there were populations with high ant abundance where $P$. alcon was absent, ant abundance was rarely low in populations where it was present. Among populations where the butterfly seed predator was present, neither the proportion of plants with $P$. alcon eggs (2010: $\beta=-3.74, P=0.571 ; 2011$ : $\beta=-5.31, P=0.246)$ nor the mean number of eggs per plant (2010: $\beta=-0.30, P=0.552 ; 2011: \beta=-0.61$, $P=0.575$ ) were significantly related to ant abundance.

\section{Discussion}

In this study, we have shown that the butterfly predispersal seed predator $P$. alcon shifts the direction of phenotypic selection on flowering phenology in its host plant G. pneumonanthe. In the absence of the butterfly, phenotypic selection favored earlier flowering. Because $P$. alcon preferentially attacked earlier-flowering individuals within populations, selection favored later flowering in populations where the butterfly was present. Moreover, the incidence of the butterfly in host plant populations was higher in populations with a high abundance of host ants, suggesting that the community context in terms of the second host of the butterfly might influence selection on flowering phenology in the host plant.

In late-flowering plant species like G. pneumonanthe, earlier flowering might be beneficial at higher latitudes, where the growing season is short, because it increases the time and resources available for seed maturation (Aizen 2003, Munguía-Rosas et al. 2011b). The pattern of earlyflowering plants having higher fitness in the absence of butterfly seed predators found in G. pneumonanthe is consistent with the general trend suggested by MunguíaRosas et al. (2011b). It is important, however, to bear in mind that higher fitness in earlier-flowering plants could result from early flowering directly increasing fitness, e.g., by increasing time and resources for seed maturation, or from other plant traits correlated with early flowering

TABLE 3. Effects of population, flowering phenology, flower number and shoot height on the probability $(0$ or 1$)$ and intensity (number of eggs in all individuals) of attack by P. alcon in 10 populations of the plant G. pneumonanthe in 2010 ( $\mathrm{N}=1000$ plants) and 11 populations in 2011 ( $\mathrm{N}=1099$ plants) where the butterfly seed predator was present. $\chi^{2}$-values are shown for logistic regressions, and $F$ values for linear regressions. Estimates from a model without interaction terms are given for significant main effects where the interaction with population is not significant. Traits were standardized within populations before analyses.

\begin{tabular}{|c|c|c|c|c|c|c|c|c|c|c|}
\hline \multirow[b]{3}{*}{ Source of variation } & \multicolumn{6}{|c|}{ Response: probability of attack } & \multicolumn{4}{|c|}{ Response: intensity of attack } \\
\hline & \multicolumn{3}{|c|}{2010} & \multicolumn{3}{|c|}{2011} & \multicolumn{2}{|r|}{2010} & \multicolumn{2}{|r|}{2011} \\
\hline & $\mathrm{df}$ & $\chi^{2}$ & Estimate & $\mathrm{df}$ & $\chi^{2}$ & Estimate & $\mathrm{df}$ & $F$ & $\mathrm{df}$ & $F$ \\
\hline Phenology (early flowering) & 1 & $38.84 * * *$ & 0.300 & 1 & $38.24 * * *$ & 0.968 & 1 & $85.25^{* * *}$ & 1 & $47.42 * * *$ \\
\hline Flower number & 1 & $13.32 * * *$ & & 1 & $81.77 * * *$ & 0.533 & 1 & $47.12 * * *$ & 1 & $198.09^{* * *}$ \\
\hline Shoot height & 1 & 1.76 & & 1 & 0.17 & & 1 & 0.01 & 1 & 0.02 \\
\hline Population & 9 & $144.16^{* * *}$ & & 10 & $152.02 * * *$ & & 9 & $30.67 * * *$ & 10 & $56.79 * * *$ \\
\hline Population $\times$ Phenology & 9 & 9.10 & & 10 & 17.40 & & 9 & $9.28 * * *$ & 10 & $5.50^{* * *}$ \\
\hline Population $\times$ Flower number & 9 & $44.04 * * *$ & & 10 & 13.48 & & 9 & $11.92 * * *$ & 10 & $37.89^{* * *}$ \\
\hline Population $\times$ Shoot height & 9 & 10.15 & & 10 & 18.25 & & 9 & 0.52 & 10 & 0.72 \\
\hline
\end{tabular}

$* * * P<0.001$. 
TABLE 4. Standardized path coefficients for effects of reproductive traits and number of eggs laid by the butterfly $P$. alcon on the number of intact fruits in the plant G. pneumonanthe. Estimates are from saturated models fitted to each population in each year. Phen $=$ flowering phenology, Shoot $\mathrm{h}=$ shoot height, $\mathrm{N} \mathrm{fl}=$ number of flowers, $\mathrm{N}$ eggs $=$ number of eggs and $\mathrm{N}$ int fr $=$ number of intact fruits. Significant coefficients (bootstrap-corrected $P<0.05$ ) are depicted in bold, and marginally significant coefficients $(P<0.1)$ in italics.

\begin{tabular}{|c|c|c|c|c|c|c|c|c|c|c|c|}
\hline & & $\begin{array}{l}\text { Phen } \\
\rightarrow\end{array}$ & $\underset{\rightarrow}{\mathrm{N} \mathrm{fl}}$ & $\begin{array}{l}\text { Shoot h } \\
\rightarrow\end{array}$ & $\begin{array}{l}\mathrm{N} \text { eggs } \\
\stackrel{\rightarrow}{\rightarrow}\end{array}$ & $\begin{array}{l}\text { Shoot h } \\
\rightarrow\end{array}$ & $\begin{array}{l}\text { Phen } \\
\rightarrow\end{array}$ & $\underset{\mathrm{N} \mathrm{fl}}{\rightarrow}$ & $\begin{array}{c}\text { Phen } \\
\leftrightarrow\end{array}$ & $\begin{array}{c}\mathrm{N} \mathrm{fl} \\
\leftrightarrow\end{array}$ & $\begin{array}{c}\text { Phen } \\
\leftrightarrow\end{array}$ \\
\hline Population & Year & N eggs & $\mathrm{N}$ eggs & $\mathrm{N}$ eggs & $\mathrm{N}$ int $\mathrm{fr}$ & $\mathrm{N}$ int $\mathrm{fr}$ & $\mathrm{N}$ int $\mathrm{fr}$ & $\mathrm{N}$ int $\mathrm{fr}$ & Shoot h & Shoot h & $\mathrm{N}$ fl \\
\hline \multirow[t]{2}{*}{ A } & 2010 & 0.15 & 0.18 & 0.03 & -0.21 & -0.08 & -0.12 & 0.67 & 0.25 & 0.63 & 0.33 \\
\hline & 2011 & 0.31 & 0.23 & 0.05 & -0.30 & -0.37 & -0.05 & 0.91 & 0.38 & 0.71 & 0.61 \\
\hline \multirow[t]{2}{*}{ B } & 2010 & 0.06 & 0.23 & 0.20 & -0.27 & 0.13 & -0.23 & 0.46 & 0.40 & 0.49 & 0.48 \\
\hline & 2011 & 0.16 & 0.39 & 0.06 & -0.40 & 0.04 & 0.10 & 0.48 & 0.30 & 0.53 & 0.61 \\
\hline \multirow[t]{2}{*}{$\mathrm{C}$} & 2010 & 0.28 & -0.07 & 0.29 & -0.10 & -0.03 & 0.08 & 0.78 & 0.48 & 0.37 & 0.49 \\
\hline & 2011 & 0.17 & 0.57 & -0.18 & -0.10 & 0.24 & 0.01 & 0.28 & 0.58 & 0.81 & 0.53 \\
\hline $\mathrm{D}$ & 2011 & 0.17 & 0.30 & -0.02 & 0.13 & -0.03 & -0.02 & 0.18 & 0.28 & 0.42 & 0.59 \\
\hline \multirow[t]{2}{*}{ E } & 2010 & 0.10 & 0.12 & 0.01 & -0.15 & 0.09 & -0.13 & 0.49 & 0.52 & 0.73 & 0.67 \\
\hline & 2011 & 0.18 & 0.32 & -0.02 & -0.22 & -0.08 & -0.09 & 0.57 & 0.25 & 0.64 & 0.46 \\
\hline \multirow[t]{2}{*}{ F } & 2010 & 0.23 & 0.59 & -0.09 & -0.49 & -0.07 & -0.05 & 0.65 & 0.49 & 0.67 & 0.55 \\
\hline & 2011 & 0.17 & 0.64 & -0.13 & -0.23 & -0.03 & -0.10 & 0.40 & 0.56 & 0.67 & 0.62 \\
\hline \multirow[t]{2}{*}{ G } & 2010 & 0.12 & 0.51 & -0.11 & -0.14 & -0.03 & -0.31 & 0.48 & 0.38 & 0.54 & 0.51 \\
\hline & 2011 & 0.07 & 0.54 & 0.10 & -0.22 & -0.27 & 0.15 & 0.26 & 0.19 & 0.58 & 0.54 \\
\hline \multirow[t]{2}{*}{$\mathrm{H}$} & 2010 & 0.23 & 0.38 & -0.07 & -0.20 & 0.06 & -0.08 & 0.38 & 0.29 & 0.58 & 0.28 \\
\hline & 2011 & 0.38 & 0.20 & 0.06 & -0.59 & -0.04 & 0.10 & 0.62 & 0.12 & 0.52 & 0.44 \\
\hline \multirow[t]{2}{*}{ I } & 2010 & 0.46 & 0.39 & -0.04 & -0.12 & 0.16 & -0.26 & -0.02 & 0.32 & 0.33 & 0.39 \\
\hline & 2011 & 0.25 & 0.69 & -0.06 & -0.30 & -0.23 & -0.17 & 0.21 & 0.33 & 0.53 & 0.39 \\
\hline \multirow[t]{2}{*}{$\mathrm{J}$} & 2010 & 0.40 & 0.33 & 0.04 & 0.20 & 0.29 & 0.03 & 0.07 & 0.10 & 0.58 & 0.24 \\
\hline & 2011 & 0.13 & 0.66 & -0.02 & -0.15 & 0.08 & 0.07 & 0.19 & 0.23 & 0.44 & 0.52 \\
\hline \multirow[t]{2}{*}{$\mathrm{K}$} & 2010 & 0.27 & -0.16 & 0.12 & -0.28 & 0.04 & 0.02 & 0.79 & 0.57 & 0.70 & 0.58 \\
\hline & 2011 & 0.14 & 0.44 & 0.20 & -0.73 & -0.06 & 0.06 & 1.08 & 0.61 & 0.71 & 0.75 \\
\hline
\end{tabular}

having a positive effect on fitness. Positive correlations between early flowering and high fitness may also be the result of environmental covariance, i.e., both early flowering and fitness are correlated with favorable microsite conditions and high resource availability (Rausher 1992, Ehrlén 2015). In our study, we tried to alleviate problems by incorporating traits that we considered likely to be correlated with flowering phenology, as well as traits likely to be correlated with plant resource state, as covariates in our models.

In apparent contradiction to the idea that selection consistently favored early flowering when the butterfly seed predator was absent, we found a positive direct effect of later flowering on fitness after removing the effect of the number of eggs in the path models of some populations (Table 4). A possible explanation for this effect is that phenology does not only influence the total number of eggs, but also the distribution of eggs among flowers within individuals, and such effects were not accounted for in the analyses. In early-flowering plants, all flowers might develop during the period when butterflies fly, and are therefore exposed to oviposition. In lateflowering plants, however, late flowers might escape predation if they develop after the period of butterfly oviposition (cf. Mahoro 2003, Ehrlén et al. 2015). For a given egg load per plant, eggs would therefore be more aggregated in late-flowering than in early-flowering individuals, resulting in that a higher proportion of fruits escape butterfly attack.

Irrespective of the selective agents responsible for the observed selection for earlier flowering in the absence of antagonists, our results clearly show that this selection is reversed to selection for later flowering when antagonists are present. In our study system, the direction of selection on phenology differed markedly between Gentiana populations with vs. without the butterfly seed predator. This happened because $P$. alcon consistently preferred earlyflowering plants for oviposition within populations, thus increasing the relative fitness of late-flowering plants. The relationship between selection on flowering time and butterfly presence in this study was based on observational data. However, the facts that we know from direct observations (that caterpillar attack reduces fitness by larval feeding on seeds, and that butterflies preferentially oviposit on early-flowering individuals), strongly suggest that the observed relationship is indeed a causal one. Previous studies with this system have examined butterfly preferences and have shown that females of Phengaris sp. prefer to oviposit on buds that are not fully developed (corresponding to stages 1-3 in our classification), thereby increasing time available for brood feeding and development (Thomas and Elmes 2001, Patricelli et al. 2011). Our study showed that plants starting bud development early in the season are the most prone to be 
A) $\mathrm{n}=1000 ; \chi^{2}=1.05 ;$ Bollen-Stine $\mathrm{P}=0.413$

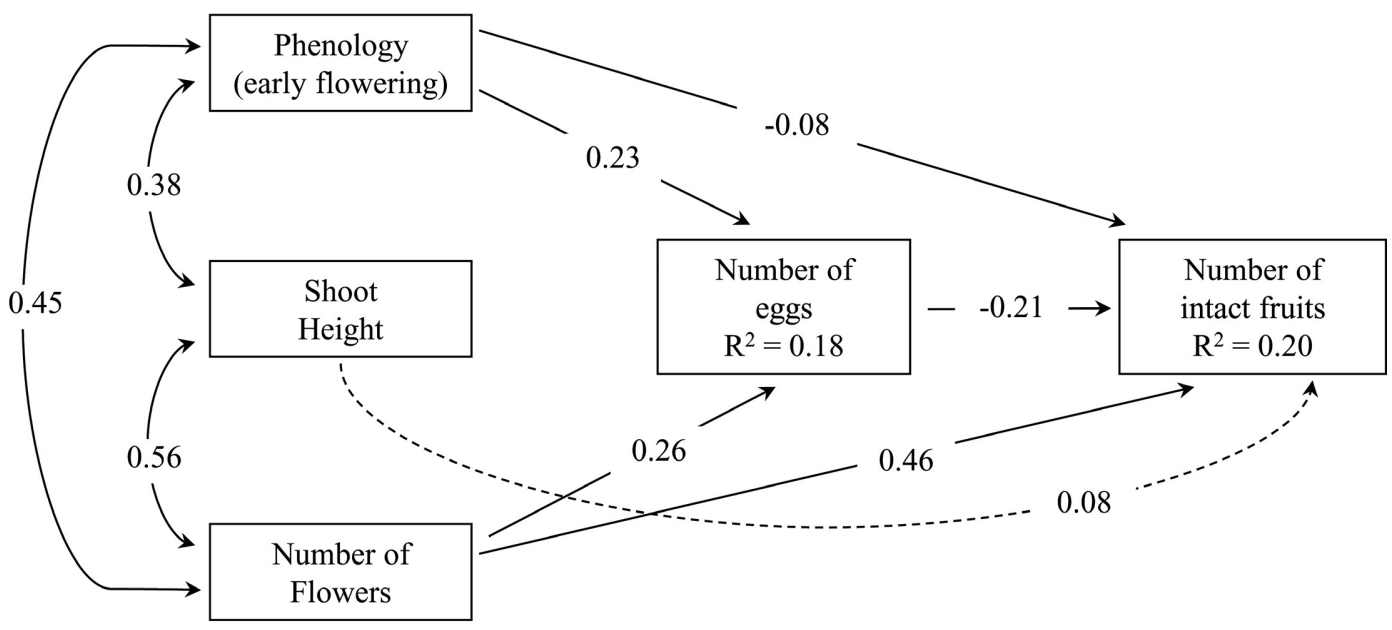

B) $\mathrm{n}=1099 ; \chi^{2}=0.56$; Bollen-Stine $\mathrm{P}=0.746$

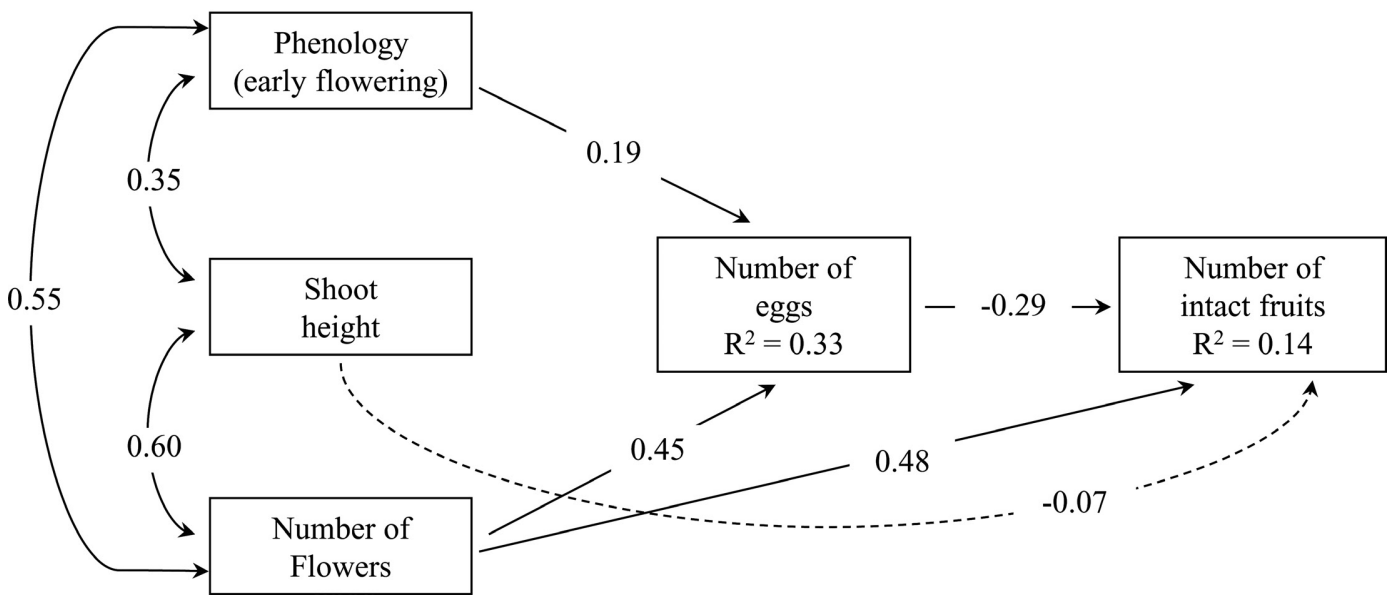

FIG. 2. Path models of the effects of plant reproductive traits (flowering phenology, shoot height, and number of flowers) and intensity of predation (number of eggs) by the butterfly $P$. alcon on the number of intact fruits in G. pneumonanthe in 2010 (A) and 2011 (B). The model with the lowest AICc is shown in each case. Dashed arrows indicate non-significant path coefficients. $R^{2}$-values are shown in the boxes of endogenous variables. All data were standardized within populations before analyses. Sample size ( $\mathrm{N}=$ number of plant individuals), $\chi^{2}$ and Bollen-stine $P$-value are shown.

attacked by the butterfly. This is most likely because the presence of the preferred floral developmental stages overlaps more with the oviposition period of $P$. alcon than in late-flowering plants, although the relative abundance of flowers over the season might also influence the probability of a plant individual being oviposited (cf. Weis and Kapelinski 1994). Our findings with G. pneumonanthe agree with studies in other systems demonstrating predator-mediated selection for late flowering (Pilson 2000, Kolb et al. 2007a, Parachnowitsch and Caruso 2008), although selection for early flowering has also been reported (Kolb et al. 2007a).

Although most plant populations where the butterfly seed predator was present experienced selection for later flowering in our study, the intensity of this selection varied. The fact that these differences in intensity of selection were not related to butterfly predation intensity within populations suggests that other unidentified factors, such as temperature or humidity, contributed to net selection on flowering phenology. Our study was observational and the causal relationships suggested by the analyses were not experimentally tested. It is thus possible that unmeasured environmental factors might have influenced both incidence of the butterfly seed predator and mean phenology or fitness. Indeed, combinations of populations and years with earlier mean phenology showed higher proportions of plants attacked by the butterfly (binomial GLM, $\beta=0.528, P<0.001$ ), suggesting that this seed predator not only prefers earlier-flowering plants within populations, but also tends to be associated 


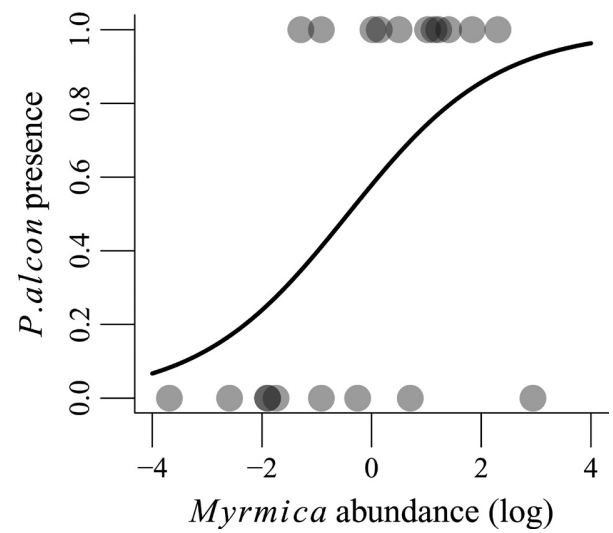

FIG. 3. Relationship between abundance of Myrmica host ants (log mean number of observed individuals), and presence/ absence of $P$. alcon in populations of $G$. pneumonanthe (fitted curve is a logistic regression, $\mathrm{N}=20$ populations, $P=0.045$ ).

with earlier-flowering populations. However, differences in selection gradients among populations were not related to mean phenology $(2010: \beta=0.19, P=0.250 ; 2011: \beta=$ $0.12, P=0.281$ ). This suggests differences in mean phenology among the study populations did not strongly bias our main results. In conclusion, our results with G. pneumonanthe demonstrate that the presence of antagonists in plant populations can shift the direction of selection, and that the distribution of antagonists among plant populations is strongly related to the observed patterns of among-population variation in the direction of selection.

The effects of shoot height on butterfly oviposition differed among plant populations and between years according to the path analyses. Taller shoots are more conspicuous and visually attractive (Nowicki et al. 2005) and might also constitute safer oviposition sites for the female butterflies (Van Dyck and Regniers 2010). Moreover, eggs laid on taller shoots might experience higher temperatures and a more suitable microclimate for larval growth (Alonso 1997). The differences in the preference for taller shoots among populations found in our study suggest that the positive effect of higher shoots is relatively weak and depends on environmental context. One possible explanation for this pattern is that the preference for taller shoots is stronger in populations with high vegetation surrounding the plants, as only tall shoots protrude from the canopy and are easily spotted by the butterflies (cf. Küer and Fartmann 2005).

Given that our results link among-population differences in the direction of selection on flowering phenology to the incidence of the butterfly seed predator, the next step in understanding how environmental variation influences selection is to identify the factors influencing butterfly distribution and abundance. In our study system, $P$. alcon was more likely to be present in host plant populations with a high abundance of Myrmica ants. This finding agrees with what is known about the biology of the butterfly, which is unable to complete its life cycle without ants. In order to be able to reach their final size, pupate, and eclose as adults, caterpillars need to be fed in the ant nest (Mouquet et al. 2005). Although we did not demonstrate a causal relationship between ant abundance and butterfly presence, our correlative results together with the dependence of the butterfly on ant presence suggest that the observed among-population variation in selection on plant flowering phenology mediated by the butterfly seed predator is influenced by the abundance of its second host, and environmental factors determining ant abundance. Several other studies showing that selection on plant traits by mutualists and antagonists is altered by interactions with other community members (Biere and Tack 2013, Fedriani and Delibes 2013, Arceo-Gómez and Ashman 2014), also suggest that the community context has important effects on the outcome of plant-animal interactions.

In this study, we examined how seed predators influenced selection on flowering time by estimating effects on one fitness component, fruit production. To assess the likelihood that observed differences in the direction of selection on flowering time translate into population divergence, we also need to know how well our fitness component correlates with lifetime fitness, how consistent differences in selection (i.e., persistence of butterfly populations) are over time, and to what extent there is genetic variation in flowering time. Although it is true that selective agents acting on other components of fitness might influence net selection on flowering time, our study should still provide a reliable picture of the part of selection on flowering time that is mediated by predispersal seed-predators. Regarding genetic variation, we know through common garden experiments that there are significant, genetically based differences among populations in flowering phenology (A. Valdés and J. Ehrlén, unpublished data). However, we still lack data from a sufficient number of populations to confirm if these differences are related to the presence of the butterfly seed predator in the population of origin.

A key objective in the study of evolutionary adaptation is to link variation in natural selection to variation in the environment. Given that much of the variation in natural selection is driven by biotic interactions, assessing the drivers of variation in natural selection requires both identifying the relevant selective agents and examining how the environmental context of the interactions influences the incidence and abundance of the interacting species. While many recent studies have demonstrated ubiquitous variation in selection among populations and years, the environmental drivers responsible for this variation have rarely been fully identified (Siepielski et al. 2013). This study took two important steps towards identifying the drivers of among-population variation in natural selection by showing both that variation in the direction of selection on timing of reproduction in a host plant is driven by the presence of a seed predator, and that the presence of the predator is associated with the abundance of a second host. 


\section{AcKnowledgments}

We thank Susanne Govella, Anna Herrström, and Jessica Oremus for field data collection, Johan P. Dahlgren for statistical advice and Ove Eriksson, Per-Olof Wickman and Arthur E. Weis for valuable comments on a previous version of the manuscript. We acknowledge funding from the Swedish Research Council (VR) to JE and from the "Clarín" postdoctoral program (FICYT, Gobierno del Principado de Asturias, Spain, and Marie Curie-Cofund Actions, EU) to AV.

\section{Literature Cited}

Aizen, M. A. 2003. Influences of animal pollination and seed dispersal on winter flowering in a temperate mistletoe. Ecology 84:2613-2627.

Alonso, C. 1997. Choosing a place to grow. Importance of within-plant abiotic microenvironment for Yponomeuta mahalebella. Entomologia Experimentalis et Applicata 83: 171-180.

Als, T. D., R. Vila, N. P. Kandul, D. R. Nash, S.-H. Yen, Y.-F. Hsu, A. A. Mignault, J. J. Boomsma, and N. E. Pierce. 2004. The evolution of alternative parasitic life histories in large blue butterflies. Nature 432:386-390.

Appelqvist, T., and O. Bengtsson. 2007. Åtgärdsprogram för alkonblåvinge och klockgentiana 2007-2011: Maculinea alcon och Gentiana pneumonanthe. Naturvårdsverket, Stockholm, Sweden.

Arbukle, J. L. 2007. AMOS 16 Users Guide.

Arceo-Gómez, G., and T.-L. Ashman. 2014. Coflowering community context influences female fitness and alters the adaptive value of flower longevity in Mimulus guttatus. The American Naturalist 183:E50-E63.

Arnold, S. J. 1986. Limits on stabilizing, disruptive, and correlational selection set by the opportunity for selection. The American Naturalist 128:143-146.

Arvanitis, L., C. Wiklund, and J. Ehrlén. 2007. Butterfly seed predation: Effects of landscape characteristics, plant ploidy level and population structure. Oecologia 152: 275-285.

Austen, E. J., and A. E. Weis. 2015. What drives selection on flowering time? An experimental manipulation of the inherent correlation between genotype and environment. Evolution 69:2018-2033.

Benkman, C. W. 2013. Biotic interaction strength and the intensity of selection. Ecology Letters 16:1054-1060.

Benkman, C. W., J. W. Smith, M. Maier, L. Hansen, and M. V. Talluto. 2013. Consistency and variation in phenotypic selection exerted by a community of seed predators. Evolution 67:157-169.

Biere, A., and A. J. M. Tack. 2013. Evolutionary adaptation in three-way interactions between plants, microbes and arthropods. Functional Ecology 27:646-660.

Bollen, K. A., and R. A. Stine. 1993. Bootstrapping goodnessof-fit measures in structural equation models. Pages 111135 in K. A. Bollen, and J. S. Long, editors. Testing structural equation models. Sage Publications, Newbury Park.

Chamberlain, S. A., J. L. Bronstein, and J. A. Rudgers. 2014. How context dependent are species interactions? Ecology Letters 17:881-890.

Chapurlat, E., J. Ågren, and N. Sletvold. 2015. Spatial variation in pollinator-mediated selection on phenology, floral display and spur length in the orchid Gymnadenia conopsea. New Phytologist 208:1264-1275.

Ehrlén, J. 2015. Selection on flowering time in a life-cycle context. Oikos 124:92-101.
Ehrlén, J., and Z. Münzbergová. 2009. Timing of flowering: Opposed selection on different fitness components and trait covariation. The American Naturalist 173:819-830.

Ehrlén, J., J. Raabova, and J. P. Dahlgren. 2015. Flowering schedule in a perennial plant; life-history trade-offs, seed predation, and total offspring fitness. Ecology 96:2280-2288.

Elzinga, J. A., A. Atlan, A. Biere, L. Gigord, A. E. Weis, and G. Bernasconi. 2007. Time after time: flowering phenology and biotic interactions. Trends in Ecology and Evolution 22:432-439.

Fedriani, J. M., and M. Delibes. 2013. Pulp feeders alter plant interactions with subsequent animal associates. Journal of Ecology 101:1581-1588.

Franks, S. J., S. Sim, and A. E. Weis. 2007. Rapid evolution of flowering time by an annual plant in response to a climate fluctuation. Proceedings of the National Academy of Sciences 104:1278.

Fukano, Y., K. Tanaka, and T. Yahara. 2013. Directional selection for early flowering is imposed by a re-associated herbivore - but no evidence of directional evolution. Basic and Applied Ecology 14:387-395.

Giménez-Benavides, L., R. García-Camacho, J. M. Iriondo, and A. Escudero. 2011. Selection on flowering time in Mediterranean high-mountain plants under global warming. Evolutionary Ecology 25:777-794.

Grace, J. B. 2006. Structural equation modeling and natural systems. Cambridge University Press, Cambridge, UK.

Kolb, A., J. Ehrlén, and O. Eriksson. 2007a. Ecological and evolutionary consequences of spatial and temporal variation in pre-dispersal seed predation. Perspectives in Plant Ecology, Evolution and Systematics 9:79-100.

Kolb, A., R. Leimu, and J. Ehrlén. 2007b. Environmental context influences the outcome of a plant-seed predator interaction. Oikos 116:864-872.

Kolb, A., and J. Ehrlén. 2010. Environmental context drives seed predator-mediated selection on a floral display trait. Evolutionary Ecology 24:433-445.

König, M. A. E., C. Wiklund, and J. Ehrlén. 2015. Timing of flowering and intensity of attack by a butterfly herbivore in a polyploid herb. Ecology and Evolution 5:1863-1872.

Küer, A., and T. Fartmann. 2005. Prominent shoots are preferred: Microhabitat preferences of Maculinea alcon (Denis \& Schiffermüller, 1775) in Northern Germany (Lycaenidae). Nota Lepidoptera 27:309-319.

Lande, R., and S. J. Arnold. 1983. The measurement of selection on correlated characters. Evolution 37:1210.

Mahoro, S. 2003. Effects of flower and seed predators and pollinators on fruit production in two sequentially flowering congeners. Plant Ecology 166:37-48.

Mouquet, N., V. Belrose, J. A. Thomas, G. W. Elmes, and R. T. Clarke. 2005. Conserving community modules: a case study of the endangered lycaenid butterfly Maculinea alcon. Ecology 86:3160-3173.

Munguía-Rosas, M. A., J. Ollerton, and V. Parra-Tabla. 2011 a. Phenotypic selection on flowering phenology and size in two dioecious plant species with different pollen vectors. Plant Species Biology 26:205-212.

Munguía-Rosas, M. A., J. Ollerton, V. Parra-Tabla, and J. A. De-Nova. 2011b. Meta-analysis of phenotypic selection on flowering phenology suggests that early flowering plants are favoured. Ecology Letters 14:511-521.

Nash, D. R., T. D. Als, R. Maile, G. R. Jones, and J. J. Boomsma. 2008. A mosaic of chemical coevolution in a Large Blue butterfly. Science 319:88-90.

Nowicki, P., M. Witek, P. Skorka, and M. Woyciechowski. 2005. Oviposition patterns in the myrmecophilous butterfly Maculinea alcon Denis \& Schiffermueller (Lepidoptera: 
Lycaenidae) in relation to characteristics of foodplants and presence of ant hosts. Polish Journal of Ecology 53:409-417.

Oostermeijer, J. G. B., J. C. M. Den Nijs, L. E. L. Raijmann, and S. B. J. Menken. 1992. Population biology and management of the marsh gentian (Gentiana pneumonanthe L.), a rare species in The Netherlands. Botanical Journal of the Linnean Society 108:117-130.

Parachnowitsch, A. L., and C. M. Caruso. 2008. Predispersal seed herbivores, not pollinators, exert selection on floral traits via female fitness. Ecology 89:1802-1810.

Patricelli, D., F. Barbero, V. La Morgia, L. P. Casacci, M. Witek, E. Balletto, and S. Bonelli. 2011. To lay or not to lay: oviposition of Maculinea arion in relation to Myrmica ant presence and host plant phenology. Animal Behaviour 82:791-799.

Pilson, D. 2000. Herbivory and natural selection on flowering phenology in wild sunflower, Helianthus annuus. Oecologia 122:72-82.

R Development Core Team. 2014. R: A language and environment for statistical computing. R Foundation for Statistical Computing, Vienna, Austria. http://www.R-project.org/

Rausher, M. D. 1992. The measurement of selection on quantitative traits: biases due to environmental covariances between traits and fitness. Evolution 46:616-626.

Rey, P. J., C. M. Herrera, J. Guitián, X. Cerdá, A. M. SanchezLafuente, M. Medrano, and J. L. Garrido. 2006. The geographic mosaic in predispersal interactions and selection on Helleborus foetidus (Ranunculaceae). Journal of Evolutionary Biology 19:21-34.

Sala, M., L. P. Casacci, E. Balletto, S. Bonelli, and F. Barbero. 2014. Variation in butterfly larval acoustics as a strategy to infiltrate and exploit host ant colony resources. PLoS ONE 9:e94341.

Sandring, S., and J. Ågren. 2009. Pollinator-mediated selection on floral display and flowering time in the perennial herb Arabidopsis lyrata. Evolution 63:1292-1300.
Siepielski, A. M., and C. W. Benkman. 2007. Selection by a predispersal seed predator constrains the evolution of avian seed dispersal in pines. Functional Ecology 21:611-618.

Siepielski, A. M., K. M. Gotanda, M. B. Morrissey, S. E. Diamond, J. D. DiBattista, and S. M. Carlson. 2013. The spatial patterns of directional phenotypic selection. Ecology Letters 16:1382-1392.

Simmonds, N. W. 1946. Gentiana pneumonanthe L. Journal of Ecology 33:295-307.

Sletvold, N., K. K. Moritz, and J. Ågren. 2015. Additive effects of pollinators and herbivores result in both conflicting and reinforcing selection on floral traits. Ecology 96:214-221.

Strauss, S. Y., and R. E. Irwin. 2004. Ecological and evolutionary consequences of multispecies plant-animal interactions. Annual Review of Ecology, Evolution, and Systematics 35:435-466.

Thomas, J. A., and G. W. Elmes. 2001. Food-plant niche selection rather than the presence of ant nests explains oviposition patterns in the myrmecophilous butterfly genus Maculinea. Proceedings of the Royal Society of London B: Biological Sciences 268:471-477.

Thompson, J. N. 2005. The geographic mosaic of coevolution. First edition. University of Chicago Press, Chicago.

Van Dyck, H., and S. Regniers. 2010. Egg spreading in the ant-parasitic butterfly, Maculinea alcon: from individual behaviour to egg distribution pattern. Animal Behaviour 80: 621-627.

Vanhoenacker, D., J. Ågren, and J. Ehrlén. 2013. Non-linear relationship between intensity of plant-animal interactions and selection strength. Ecology Letters 16:198-205.

von Euler, T., J. Ågren, and J. Ehrlén. 2014. Environmental context influences both the intensity of seed predation and plant demographic sensitivity to attack. Ecology 95:495-504.

Weis, A. E., and A. Kapelinski. 1994. Variable selection on Eurosta's Gall size. II. A path analysis of the ecological factors behind selection. Evolution 48:734-745.

\section{SUPPORTING INFORMATION}

Additional supporting information may be found in the online version of this article at http://onlinelibrary.wiley.com/ doi/10.1002/ecy.1633/suppinfo 